\title{
Smartphone-Acquired Image Photogrammetry for Detection of Shallow Anterior Chamber
}

\section{Ravi Chandna \\ Neetha IR Kuzhuppilly \\ Yogish S Kamath (D)}

Department of Ophthalmology, Kasturba Medical College-Manipal, Manipal Academy of Higher Education, Manipal, 576104, India
Correspondence: Yogish S Kamath Email yogish.kamath@manipal.edu
Purpose: This study aimed to explore the role of smartphone imaging of the eye using two perspectives - anterior and temporal - in the detection of a shallow anterior chamber (AC). The AC depth (ACD) of an eye can be used as a surrogate marker for identification of eyes at risk of developing angle-closure disease.

Methods: A prospective observational study was conducted at a university teaching hospital in South India. Each eye was photographed with a smartphone using the two perspectives, followed by quantitative measurement of ACD using optical biometry. The percentage of nasal iris illuminated was measured from the image acquired using the flashlight method (anterior perspective), whereas pupil position relative to the cornea was measured from the image acquired using the temporal perpendicular method (temporal perspective). The receiver-operating characteristic curve and area under the curve (AUC) were studied for both perspectives independently for overall predictive accuracy in detection of shallow AC (ACD $<2.7 \mathrm{~mm}$, obtained by IOL Master).

Results: A total of 275 eyes were examined, of which 77 (28\%) had an ACD $<2.7 \mathrm{~mm}$. The accuracy of detection of shallow AC was found to be $95.2 \%$ for both perspectives when used alone or in combination. AUC of the anterior perspective was 0.99 (95\% CI 0.982-0.997). The AUC for the temporal perspective was 0.993 (95\% CI 0.988-0.999).

Conclusion: Smartphone-acquired image photogrammetry of an eye with anterior and temporal perspectives independently and in combination provided accuracy nearing $95 \%$ in the detection of shallow AC $(\mathrm{ACD}<2.7 \mathrm{~mm})$.

Registration: This trial was registered with the Clinical Trial Registry of India (CTRI/2018/ 09/015867, September 28, 2018).

Keywords: flashlight test, angle-closure glaucoma, shallow anterior chamber, community screening, smartphone teleophthalmology, telemedicine

\section{Introduction}

Glaucoma is the principal cause of irreversible blindness in the world. ${ }^{1}$ As of 2020, the estimated number of cases globally stood at approximately 75 million. ${ }^{1}$ Of these, primary angle-closure glaucoma (PACG) accounted for approximately 25 million cases, $80 \%$ of which were found in Asia (China $>$ India $>$ Southeast Asia). ${ }^{1}$ PACG is predominantly asymptomatic in the Asian population ${ }^{2}$ and $>90 \%$ of the cases go undiagnosed, making it difficult to study the true prevalence. ${ }^{3}$ The relative lack of health-care resources in some of these countries is another factor contributing to its underestimation.

Although less prevalent than open-angle glaucoma, angle-closure disease carries triple the risk of causing severe bilateral visual impairment. ${ }^{2}$ Current diagnostic 
techniques of angle closure require sophisticated infrastructure and skilled professionals, both of which are deficient in most developing countries with a high prevalence of PACG.

Therefore, there is a dire need for standardized community-screening methods using ubiquitous tools, such as smartphones, for early detection and referral of patients at risk of developing angle-closure disease in countries with low ophthalmologist:population ratios. Marchini et al showed that a shallow anterior chamber (AC) is the single most important biometric determinant predisposing to angle-closure disease. ${ }^{4}$ Kurita et al showed that central $\mathrm{AC}$ depth (ACD) is a better predictor of primary angle closure than $\mathrm{AC}$ angle or $\mathrm{AC}$ volume. ${ }^{5}$ Multiple studies have confirmed central ACD as a good surrogate marker for development of angle-closure disease, ${ }^{3-5}$ making it an ideal parameter that can be used as a screening tool.

Although convenient, existing screening techniques for central ACD, such as the flashlight test, are not considered reliable by ophthalmologists, due to lack of sufficient accuracy. ${ }^{6}$ In this study, we aimed to improve the traditional flashlight test (also known as the oblique illumination test) by standardization of the technique and by objective analysis of the test with smartphone imaging. A novel method, described as temporal perpendicular digital photography by Zamir et al, ${ }^{7}$ was found to have good agreement with ACD values, and was hence included in this study for its possible utility in detecting shallow AC.

Both these methods, individually and in combination, were then evaluated for their ability to detect shallow AC, the depth of which was determined by optical biometry.

\section{Methods}

This was a hospital-based study conducted at a university teaching hospital in coastal Karnataka, southern India. Institutional ethical committee clearance was obtained (IEC: 497-2018), after which the study was registered with the Clinical Trial Registry of India (CTRI/2018/09/ 015867). Principles of the Declaration of Helsinki were adhered to.

\section{Participants}

One patient volunteer aged $>18$ years was enrolled in the study every alternate day. Exclusion criteria were corneal/ limbal opacities, history of any ocular surgery (including but not limited to cataract surgery, pterygium excision surgery, and glaucoma surgery), and had undergone peripheral iridotomy or any form of ocular laser treatment.
Assuming a prevalence of shallow AC of 5\%, to achieve sensitivity and accuracy of $95 \%$, the sample size was calculated to be 275 eyes.

\section{Image and Data Acquisition}

After informed consent and patient demographic details had been acquired, each volunteer was seated in a well-lit room and asked to focus on a distant target. Each eligible eye was photographed from two perspectives using a flashlight (25W LED pen-torch, white light, intensity $250 \mathrm{~lm}$ ) and an Android smartphone (Samsung Galaxy S9+ SM-G965F) in "auto" mode at the highest resolution offered with the flash off. The first method involved imaging the eye from the anterior perspective with the camera held in the visual axis while illuminating the eye from the temporal side using the flashlight, similarly to the flashlight test described by van Herrick et al. ${ }^{10}$ Careful consideration was given to acquiring the image when corneal reflex from the flashlight was at the temporal limbus, as demonstrated in Figure 1A.

The second method involved imaging the eye from the temporal perspective, with the smartphone camera held perpendicularly to the visual axis using the method described by Zamir et al. ${ }^{7}$ A slight modification was made to their technique, wherein the eye was illuminated from below by a flashlight at a $45^{\circ}$ angle.

The ACD of each eye was then quantitatively measured using an IOL Master 500 (Carl Zeiss Meditec, Jena, Germany) in "auto" mode. Both the photography and optical biometry were performed by the same investigator.

\section{Photogrammetric Analysis}

For each eye, the image with the best resolution and clearest visualization of the anterior segment was chosen for analysis.

Each photograph was then analyzed on a laptop computer using a pixel ruler (Ruler tool in Adobe Photoshop CC 2015), and the following data obtained.

\section{Anterior Perspective}

The amount of nasal iris illuminated was calculated, as shown in Figure 1A. On a straight horizontal line joining the nasal pupillary edge and the nasal limbus, the value "I" (illumination) was calculated as the distance from the pupillary edge till the start of the iris shadow. The value "S" (shadow) was calculated as the distance from the start of iris shadow till the nasal limbus. The amount of nasal iris illumination was expressed as the ratio of $[\mathrm{I}: \mathrm{I}+\mathrm{S}]$. If 


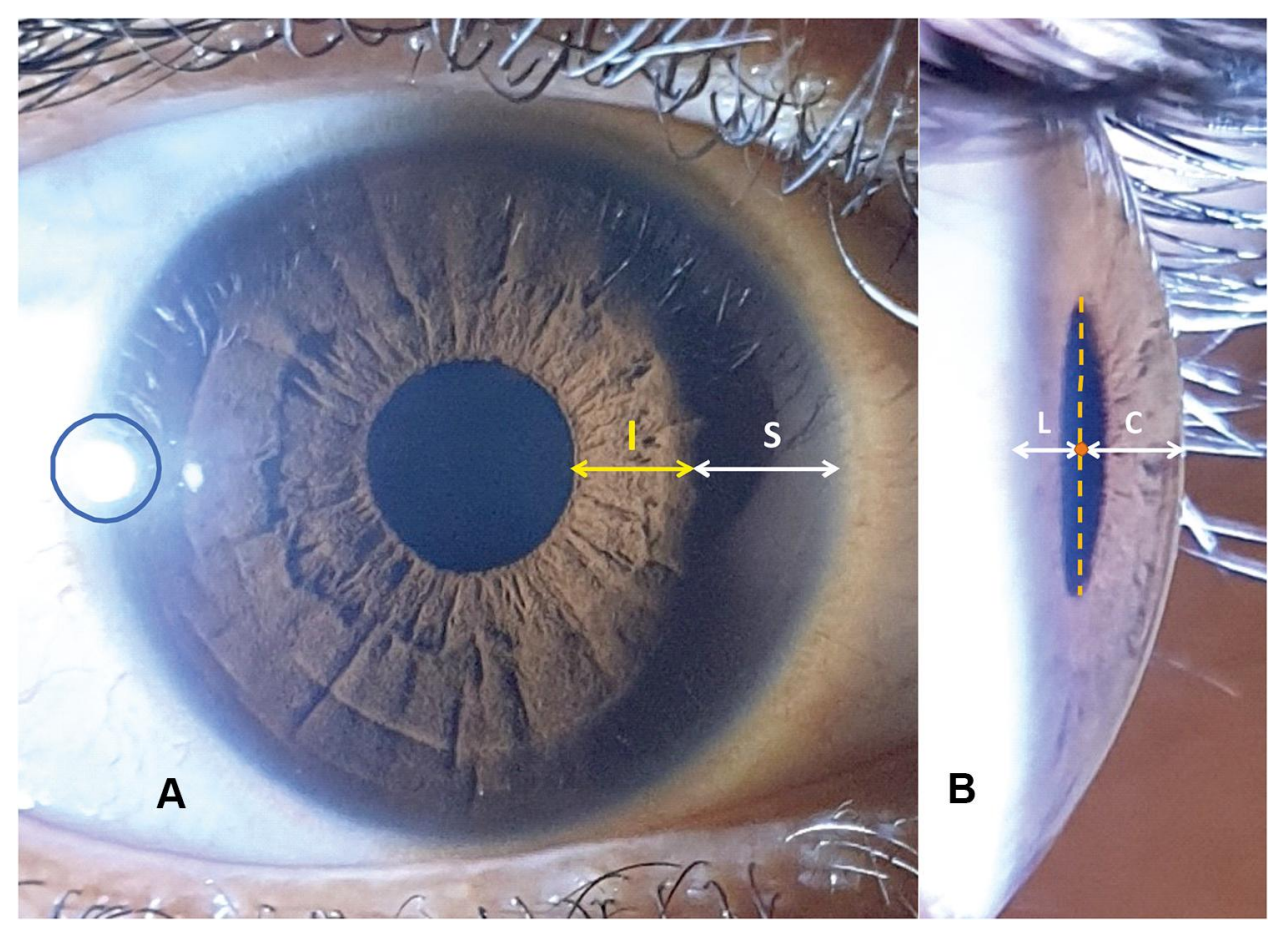

Figure I Photogrammetry of images on anterior and temporal perspectives. (A) Estimation of nasal iris illumination on anterior perspective (image acquired using flashlight method). Corneal reflex at temporal limbus surrounded by blue circle. I, distance between nasal pupillary border and start of iris shadow; $\mathrm{S}$, distance between start of iris shadow and nasal limbus. (B) Relative position of midpoint of pupil to corneal apex and temporal limbus (image acquired using the temporal perpendicular method). C, distance of midpoint of pupil from corneal apex; L, distance of midpoint of pupil from temporal limbus. Midpoint of pupil determined as midpoint of vertical line joining superior and inferior pupillary edges.

the ratio obtained were $\leq 0.5$, it was classified as shallow, and if $>0.5$, it was classified as normal. ${ }^{6}$

\section{Temporal Perspective}

On a straight line joining the apex of cornea, midpoint of pupil, and temporal limbus, relative pupil position was measured, as shown in Figure 1B. The midpoint of pupil was determined as the midpoint on a vertical line joining the superior and inferior pupillary edge. $\mathrm{C}$ represents distance between apex of cornea to midpoint of pupil, $\mathrm{L}$ midpoint of pupil to temporal limbus. Relative pupil position was expressed as the ratio of $[\mathrm{C}: \mathrm{C}+\mathrm{L}]$. The closer the pupil position to the cornea, the smaller the ratio. If the ratio were $\leq 0.5$ it was classified as shallow, and if $>0.5$, it was classified as normal.

\section{Combination Criterion}

This was the only qualitative measure of our study. A sample was classified as "shallow" if the calculated ratio from either of the aforementioned tests were shallow. A sample was classified as "normal" only when ratios from these two tests were normal. All data were then entered into an Excel spreadsheet, then analyzed using SPSS 23.0. The process of photogrammetry was done at random, and the investigator was masked to biometry data at the time of image analysis.

\section{Determining Shallow Anterior-Chamber Cutoff}

Since there were no conclusive data in our population to define a cutoff value for ACD on optical biometry below which there was increased risk of developing angle-closure disease, $2.7 \mathrm{~mm}$ was derived from few studies that had analyzed the biometric data of patients with $\mathrm{ACG}^{8}$

On analyzing the normative data of various epidemiological studies done on Indian eyes, we found that an ACD value of $2.7 \mathrm{~mm}$ fell below one SD of mean ACD in persons aged $\geq 40$ years. $^{9}$ As such, in this study, ACD $\leq 2.7 \mathrm{~mm}$ was categorized as shallow.

\section{Statistical Analyses}

1. The receiver-operating characteristic (ROC) curve and area under the curve(AUC) were calculated individually for the anterior perspective and temporal perspective to determine their overall predictive accuracy in detecting presence or absence of shallow $\mathrm{AC}(\mathrm{ACD} \leq 2.7 \mathrm{~mm}$ using IOL Master) 
2. The ROC curve obtained was used to determine the sensitivity, specificity, and accuracy of different ratios in their ability to detect shallow ACD. The ROC curve was then utilized for arriving at an "ideal" ratio for each test, giving maximum accuracy in detecting a shallow AC of $\leq 2.7 \mathrm{~mm}$. The motive for determining this "ideal" ratio was its possible usage in future development of smartphone-based artificial intelligence-powered software that could help in community screening of shallow AC.

3. Sensitivity, specificity, and accuracy of both perspectives and their combination were calculated for different ratios to assess their ability to accurately detect shallow AC.

4. For studying interobserver variability in acquiring the two ratios from the photogrammetric analysis, the intra-class correlation coefficient (ICC) was studied using the two-way model and absolute agreement examined.

Observer 1 calculated the ratios from images of both anterior and temporal perspectives of all 275 eyes, and these values were used for the final analysis.

Observer 2 calculated the ratios from the anterior perspective only of the 275 eyes.

Observer 3 calculated the ratios from the temporal perspective only of the 275 eyes.

ICCs to measure interobserver variability for the anterior perspective were calculated between observers 1 and 2 and between observers 1 and 3 to measure correlations for the temporal perspective.

1. Using Pearson's correlation coefficient from linear regression analysis and the scatterplots, correlations among the three variables were calculated:

(i) ACD with anterior-perspective ratios

(ii) ACD with temporal-perspective ratios

(iii) Anterior-perspective ratio with temporalperspective ratios

\section{Results}

A total of 275 eyes from 143 patients were assessed. The study population consisted of $53 \%$ women and $47 \%$ men. The mean age of participants was about 51 years and mean ACD $3.04 \mathrm{~mm}$. Of the 77 eyes with shallow ACD $(\leq 2.7 \mathrm{~mm})$, mean ACD was $2.44 \pm 0.18 \mathrm{~mm}$. Of the 77 eyes with shallow AC, $52(67.5 \%)$ were from women. A summary of the demographic details of the patients and clinical characteristics of the samples is displayed in Table 1.

From the anterior perspective, 16 eyes had ratios of $\leq 0.2$ with mean ACD $2.22 \mathrm{~mm}, 67$ ratios of $0.21-0.4$ with mean ACD $2.54 \mathrm{~mm}, 105$ ratios of 0.41-0.6 with mean ACD $3.08 \mathrm{~mm}, 80$ ratios of $0.61-0.8$ with mean ACD $3.49 \mathrm{~mm}$, and seven ratios $>0.81$ with mean ACD $3.85 \mathrm{~mm}$ (Figure 2A).

From the temporal perspective, five eyes had ratios of $\leq 0.2$ with mean ACD $2.17 \mathrm{~mm}, 74$ ratios of $0.21-0.4$ with mean ACD $2.47 \mathrm{~mm}, 124$ ratios of 0.41-0.6 with ACD $3.13 \mathrm{~mm}, 68$ eyes ratios of $0.61-0.8$ with mean ACD of $3.52 \mathrm{~mm}$, and four ratios $>0.81$ with amean ACD $3.59 \mathrm{~mm}$ (Figure 2B).

The AUC of the anterior perspective was $0.990(95 \%$ CI 0.982-0.997) and of the temporal perspective 0.993

Table I Summary of Patient Demographics and Clinical Characteristics of Obtained Samples

\begin{tabular}{|c|c|c|c|}
\hline & $\begin{array}{l}\text { Males, } \\
\text { n (\%) }\end{array}$ & $\begin{array}{c}\text { Females, } \\
\text { n (\%) }\end{array}$ & $\begin{array}{l}\text { Total, } \\
\text { n (\%) }\end{array}$ \\
\hline Patients & $67(47)$ & $76(53)$ & 143 \\
\hline Eyes & $128(46.5)$ & 147 (53.5) & 275 \\
\hline Age, years (range) & $23-77$ & $23-84$ & \\
\hline $\begin{array}{l}\text { Mean age, years } \\
\text { (SD) }\end{array}$ & $49.8(17.5)$ & $52.4(17.1)$ & $51.2(17.2)$ \\
\hline \multicolumn{4}{|c|}{ Eyes by age-group $\mathrm{n}(\%)$} \\
\hline$<40$ years & 42 & 31 & $73(26.6 \%)$ \\
\hline $40-60$ & 40 & 59 & 99 (35.8\%) \\
\hline$>60$ & 46 & 57 & $103(37.6 \%)$ \\
\hline \multicolumn{4}{|c|}{ Mean ACD with IOL Master by age-group, mm (SD) } \\
\hline$<40$ years & $3.42(0.346)$ & $3.42(0.21)$ & $3.42(0.29)$ \\
\hline $40-60$ years & $3.02(0.42)$ & $2.89(0.42)$ & $2.94(0.42)$ \\
\hline$>60$ years & $2.98(0.43)$ & $2.75(0.42)$ & $2.86(0.44)$ \\
\hline Overall & $3.14(0.45)$ & $2.95(0.46)$ & $3.04(0.46)$ \\
\hline \multicolumn{4}{|c|}{ Eyes with shallow ACD $(\leq 2.7 \mathrm{~mm})$ by age-group, $\mathrm{n}$} \\
\hline$<40$ years & 2 & 0 & 2 \\
\hline $40-60$ years & 10 & 26 & 36 \\
\hline$>60$ years & 13 & 26 & 39 \\
\hline Total & 25 & 52 & 77 \\
\hline
\end{tabular}

Abbreviations $A C D$, anterior-chamber depth. 

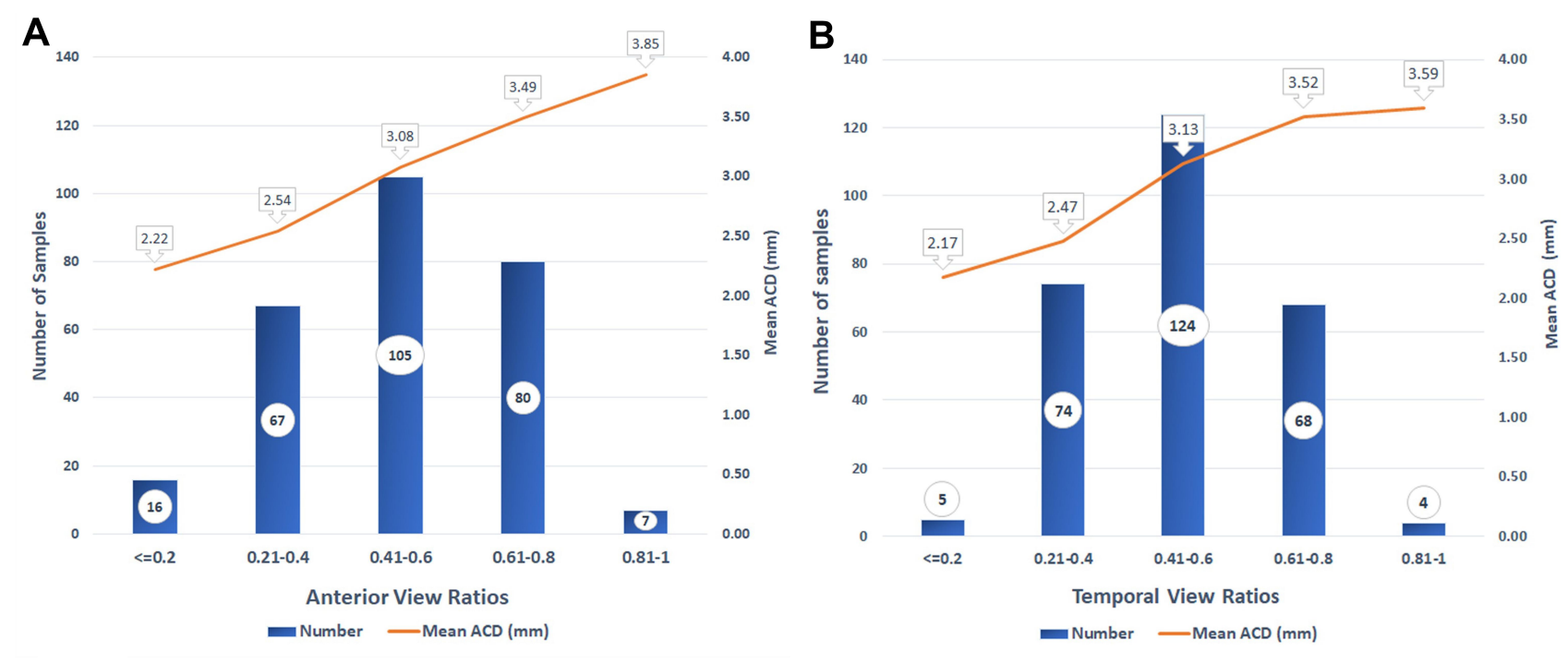

Figure 2 Samples obtained in each perspective and average ACD measured using IOL Master. (A) Photogrammetry of anterior-perspective images. The $x$-axis represents ratios obtained from the images, and the $y$-axis represents the number of samples. Mean ACD in each category is on the orange line. (B) Photogrammetry of temporal-perspective images. The $x$-axis represents ratios obtained from the images, and the $y$-axis represents the number of samples. Mean ACD in each category is on the orange line.

(95\% CI 0.988-0.999), suggesting good overall accuracy of both perspectives in detecting shallow AC (Figure 3).

We obtained sensitivity, specificity, and accuracy data for the three ratios acquired from the photogrammetric analysis in terms of ability to detect shallow AC $(\leq 2.7 \mathrm{~mm})$. A ratio $\leq 0.5$, corresponding to a $>50 \%$ iris shadow on the anterior perspective, and the pupillary midpoint being present in the anterior half on the temporal perspective, were studied for each perspective to detect shallow AC. A $\leq 0.5$-ratio cutoff for both perspectives was found to have sensitivity of $100 \%$, specificity of $75.80 \%$, and accuracy of $82.5 \%$. A $<0.34$-cutoff ratio, corresponding to a third or less of iris illumination and $>$ two-thirds iris shadow on the anterior perspective, and the pupillary midpoint being present in the anterior third in the temporal perspective, were then studied for each perspective and their combination to detect shallow AC. Sensitivity of the anterior perspective was $84.4 \%$, specificity $98 \%$, and accuracy $94.2 \%$. For the temporal perspective, sensitivity, specificity, and accuracy were $71.4 \%, 100 \%$, and $92 \%$, respectively. Combined sensitivity, combined specificity, and combined accuracy were $91 \%, 98 \%$, and $96 \%$ respectively. The ROC curve was then used to arrive at an ideal ratio of 0.4 , the use of which as a cutoff was found to have sensitivity of $93.5 \%$, specificity of $94.9 \%$, and accuracy of $94.5 \%$ for the anterior perspective, sensitivity of $93.5 \%$, specificity of $97 \%$, and accuracy of $96 \%$ for the temporal perspective, and combined sensitivity of $98.7 \%$, combined specificity of $94 \%$, and a combined accuracy of $95.2 \%$.
The combined criterion achieved higher sensitivity, specificity, and accuracy across all ratios, indicating that detection of shallow AC was improved using both perspectives, instead of relying on just one. A summary of the sensitivity, specificity, and accuracy calculated for each perspective for different ratios to detect shallow $\mathrm{AC}$ is displayed in Table 2.

The ICC for the anterior perspective was 0.96 and for the temporal perspective 0.98 , suggesting high interobserver agreement on image analysis of both the temporal and anterior perspectives. Pearson's correlation coefficients, $R^{2}$ values, and scatterplots were obtained among the threevariables (anterior-perspective ratio, temporal-perspective ratio, and $\mathrm{ACD}$ ).

The highest correlation was found between the anterior-perspective ratio and $\mathrm{ACD}\left(R=0.920, R^{2}=0.847\right)$, followed by that between the temporal-perspective ratio and $\operatorname{ACD}\left(R=0.907, R^{2}=0.823\right)$. A marginally lower correlation was found between the anterior-perspective and temporalperspective ratios $\left(R=0.901, R^{2}=0.812\right.$; Figure 4$)$.

\section{Discussion}

The presence of shallow AC is associated with multiple conditions, such as PACG, acute angle closure, intumescent cataract, plateau iris, ${ }^{11}$ hypermetropia, and even acute events like globe rupture. Therefore, early evaluation of shallow AC detected in the community may help significantly alter the course of the disease. The primary intention of this study was to enable rapid 


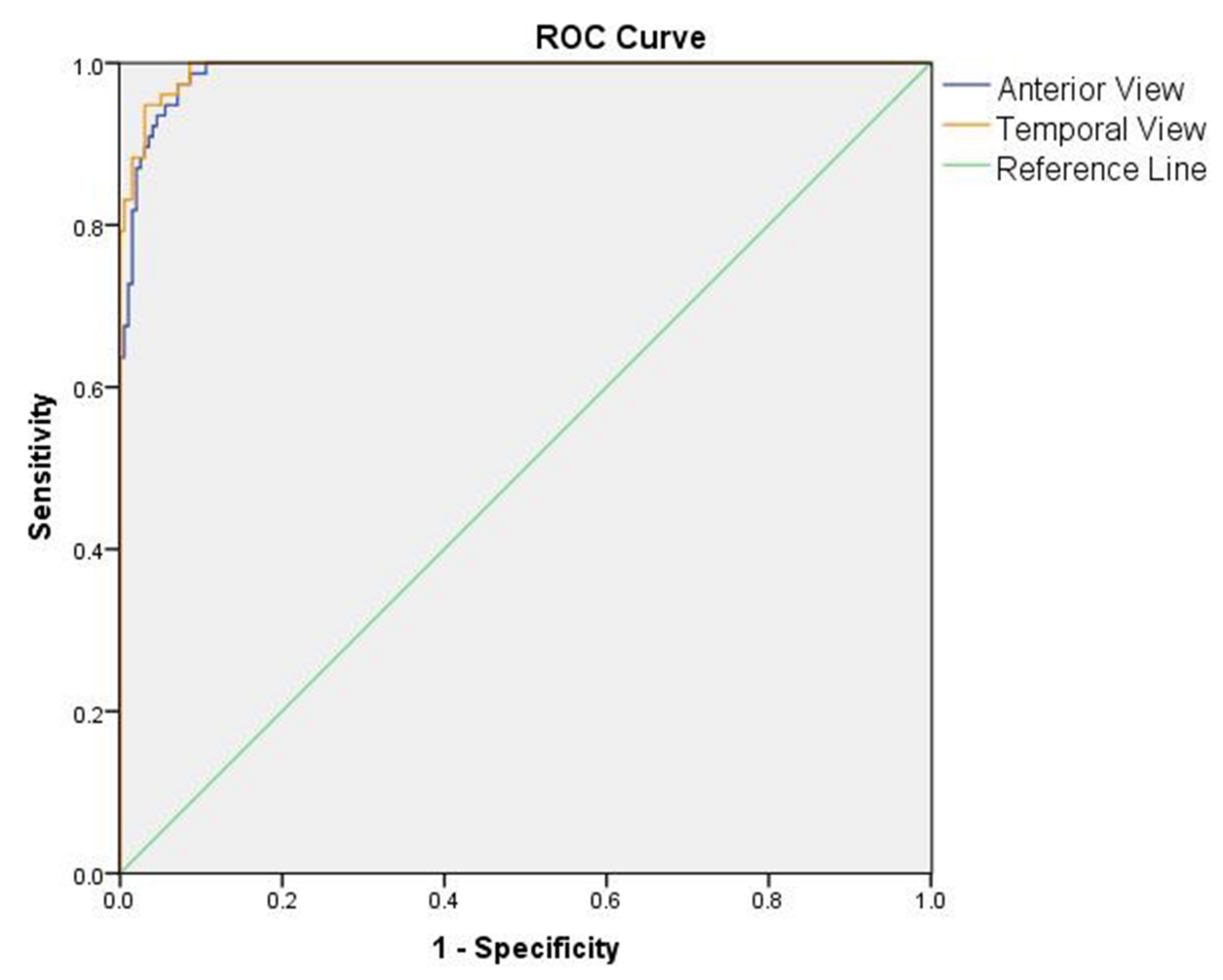

\begin{tabular}{|c|c|c|c|c|c|}
\hline \multirow{3}{*}{ Test Result Variable(s) } & \multicolumn{3}{|c|}{ Area Under the Curve } & & \\
\hline & \multirow[t]{2}{*}{ Area } & \multirow[t]{2}{*}{ Std. Errora } & \multirow[t]{2}{*}{ Asymptotic Sig. } & \multicolumn{2}{|c|}{ Asymptotic $95 \%$ Confidence Interval } \\
\hline & & & & Lower Bound & Upper Bound \\
\hline AnteriorView & .990 & .004 & .000 & .982 & .997 \\
\hline TemporalView & .993 & .003 & .000 & .988 & .999 \\
\hline
\end{tabular}

Figure 3 Receiver-operating characteristic (ROC) curve and area under the curve (AUC) of anterior and temporal perspectives. The green diagonal line is the reference (0.5), indicating the null hypothesis. The dark-blue line marks the ROC curve for the anterior perspective and the orange line the ROC curve for the temporal perspective.

and accurate detection of shallow AC using readily available tools in countries with a relative lack of health-care resources. The literature shows that traditional screening methods, such as the flashlight test, have low accuracy in detecting angle-closure disease. ${ }^{6}$ Although this technique is commonly used, it lacks adequate standardization, and various studies have classified this test into two, ${ }^{12}$ three, ${ }^{13}$ and sometimes four ${ }^{6}$ diagnostic categories. Due to this lack of global standardization and poor accuracy, there is reduced dependence on this test by ophthalmologists and lack of implementation of in community-screening programs.

As such, using two instruments (smartphone and flashlight)for imaging of the eye from two perspectives (anterior and temporal), we aimed to classify the $\mathrm{AC}$ into two groups - shallow and normal.
A comparative summary of the literature is provided in Table 3. For the anterior perspective, we assessed the ACD using the flashlight test. To the best of our knowledge, no study has described a standard manner of performing and interpreting the flashlight test. In our study, we standardized the technique by using corneal reflex from the flashlight as the landmark. When at temporal limbus, the corneal reflex gives a reliable iris shadow that may be easily reproduced. This standardization is essential for future use of this technique in mass screening, and can considerably reduce interobserver variability. For the temporal perspective, we used the novel temporal perpendicular digital photography technique, first described by Zamir et al in $2016 .^{7}$ His team proposed a temporal perspective to quantitatively measure the ACD. The method described, studied the pupillary position relative to the cornea and temporal limbus, which 
Table 2 Summary of test parameters for anterior perspective, temporal perspective, and their combination in detection of shallow AC

\begin{tabular}{|c|c|c|c|c|}
\hline Method & $\begin{array}{l}\text { Photogrammetric Ratio } \\
\text { (for Shallow AC) }\end{array}$ & $\begin{array}{c}\text { Sensitivity (True } \\
\text { Positive/Total Positive) }\end{array}$ & $\begin{array}{c}\text { Specificity (True } \\
\text { Negative/Total } \\
\text { Negative) }\end{array}$ & $\begin{array}{c}\text { Accuracy (True Positive+ True } \\
\text { Negatives/Total Samples) }\end{array}$ \\
\hline $\begin{array}{l}\text { Anterior } \\
\text { perspective }\end{array}$ & $\leq 0.50$ & $100 \%(77 / 77)$ & $75.8 \%(150 / 198)$ & $82.5 \%(227 / 275)$ \\
\hline $\begin{array}{l}\text { Temporal } \\
\text { perspective }\end{array}$ & & $100 \%$ (77/77) & $75.8 \%(150 / 198)$ & $82.5 \%(227 / 275)$ \\
\hline \multicolumn{2}{|c|}{$\begin{array}{l}\text { Combined criterion* (ratio of either } \\
\text { perspective } \leq 0.5 \text { ) }\end{array}$} & $100 \%(77 / 77)$ & $77.3 \%(153 / 198)$ & $83.6 \%(230 / 275)$ \\
\hline $\begin{array}{l}\text { Anterior } \\
\text { perspective }\end{array}$ & \multirow[t]{2}{*}{$<0.34$} & $84.4 \%(65 / 77)$ & $98 \%$ (194/198) & $94.2 \%(259 / 275)$ \\
\hline $\begin{array}{l}\text { Temporal } \\
\text { perspective }\end{array}$ & & $71.4 \%(55 / 77)$ & $100 \%(198 / 198)$ & $92 \%(253 / 275)$ \\
\hline \multicolumn{2}{|c|}{$\begin{array}{l}\text { Combined criterion* (ratio of either } \\
\text { perspective }<0.34 \text { ) }\end{array}$} & $91 \%(70 / 77)$ & $98 \%(194 / 198)$ & $96 \%(264 / 275)$ \\
\hline $\begin{array}{l}\text { Anterior } \\
\text { perspective }\end{array}$ & \multirow[t]{2}{*}{$\leq 0.4$} & $93.5 \%(72 / 77)$ & $94.9 \%(188 / 198)$ & $94.5 \%(260 / 275)$ \\
\hline $\begin{array}{l}\text { Temporal } \\
\text { perspective }\end{array}$ & & $93.5 \%(72 / 77)$ & $97 \%(192 / 198)$ & $96 \%(264 / 275)$ \\
\hline \multicolumn{2}{|c|}{$\begin{array}{l}\text { Combined criterion * (ratio of either } \\
\text { perspective } \leq 0.4 \text { ) }\end{array}$} & $98.7 \%(76 / 77)$ & $94 \%(186 / 198)$ & $95.2 \%(262 / 275)$ \\
\hline
\end{tabular}

Notes: *A sample was classified as shallow (positive) when either perspective classified it as such and normal (negative) when both perspectives classified it as such.

was used to predict ACD. Their study found a good correlation between this method and ACD. However, the use of this technique as a screening tool was not explored. Also, their study was done using a camera with the flash on in a population that predominantly consisted of eyes with light-colored irises. To study the utility of this method for screening across all populations, we modified the test so that the flashlight was shone from below at a $45^{\circ}$ angle. This enabled clear visualization of anterior-segment details. The light was not shone from the front, as it led to pupillary constriction and poor patient compliance.
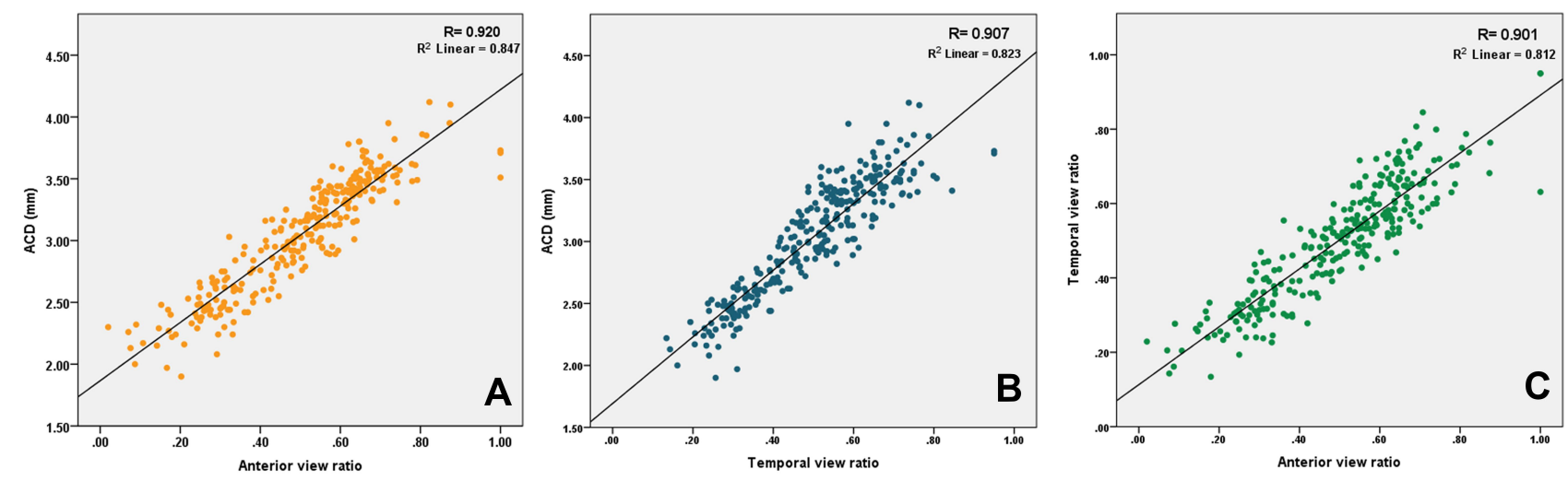

Figure 4 Scatterplots depicting correlations among the three variables. $R$, Pearson's correlation coefficient. The diagonal black line corresponds to linear $R^{2}$. (A) ACD vs anterior-perspective ratio; (B) ACD vs temporal-perspective ratio. (C) Anterior-perspective ratio vs temporal-perspective ratio. 
Table 3 Summary of existing literature on oblique flashlight test

\begin{tabular}{|c|c|c|c|c|c|c|}
\hline & $\begin{array}{l}\text { Definition of shallow } \\
\text { AC by flashlight test }\end{array}$ & $\begin{array}{l}\text { Comparative } \\
\text { measure to confirm } \\
\text { shallow AC }\end{array}$ & $\begin{array}{l}\text { Objectivel } \\
\text { subjective } \\
\text { photographic } \\
\text { assessment }\end{array}$ & $\begin{array}{l}\text { Sensitivity, } \\
\%(n)\end{array}$ & $\begin{array}{l}\text { Specificity, } \\
\%(n)\end{array}$ & $\begin{array}{l}\text { Accuracy, } \\
\% \text { (n) }\end{array}$ \\
\hline Vargas et $\mathrm{al}^{12}$ & $\begin{array}{l}\text { Nasal portion of iris in } \\
\text { shadow (presence of any } \\
\text { nasal iris shadow) }\end{array}$ & $\begin{array}{l}\text { ACD value of } \leq 2 \mathrm{~mm} \text { on } \\
\text { slit-lamp mounted } \\
\text { optical pachymeter }\end{array}$ & Subjective & $88(26 / 29)$ & $88(94 / 106)$ & $\begin{array}{l}88(120 / \\
135)\end{array}$ \\
\hline \multirow[t]{2}{*}{ Congdon et $\mathrm{al}^{13}$} & $\begin{array}{l}\text { Nasal iris shadow }>0.25 \\
\text { the distance from limbus } \\
\text { to pupillary axis }\end{array}$ & $\begin{array}{l}\text { Ultrasound ACD } \\
\leq 2.7 \mathrm{~mm}\end{array}$ & Subjective & $80(8 / 10)$ & $69(234 / 352)$ & NA \\
\hline & $\begin{array}{l}\text { Nasal iris shadow }>0.5 \\
\text { the distance from limbus } \\
\text { to pupillary axis }\end{array}$ & $\begin{array}{l}\text { Ultrasound ACD } \\
\leq 2.5 \mathrm{~mm}\end{array}$ & Subjective & $20(2 / 10)$ & $95(333 / 352)$ & NA \\
\hline \multirow[t]{2}{*}{ Thomas et $\mathrm{al}^{6}$} & $\begin{array}{l}\text { Nasal iris shadow }>0.52 \\
\text { between limbus and } \\
\text { pupillary margin }\end{array}$ & Gonioscopy & Subjective & 45 (NA) & 82 (NA) & NA \\
\hline & $\begin{array}{l}\text { Nasal Iris shadow }>0.33 \\
\text { between limbus and } \\
\text { pupillary margin }\end{array}$ & Gonioscopy & Subjective & 85 (NA) & 70 (NA) & NA \\
\hline Liwan Eye Study ${ }^{15}$ & $\begin{array}{l}\text { Iris shadow reaching } \\
\text { pupillary margin }\end{array}$ & Gonioscopy & Subjective & 76 & 81 & NA \\
\hline \multirow[t]{2}{*}{ Present study } & $\begin{array}{l}\text { Iris shadow } \geq 0.5 \text { the } \\
\text { distance from limbus to } \\
\text { pupillary margin }\end{array}$ & \multirow[t]{2}{*}{$\begin{array}{l}\text { ACD } \leq 2.7 \mathrm{~mm} \text { on } \\
\text { optical biometry (IOL } \\
\text { Master) }\end{array}$} & \multirow[t]{2}{*}{$\begin{array}{l}\text { Photographic } \\
\text { assessment }\end{array}$} & $100(77 / 77)$ & $76(150 / 198)$ & $\begin{array}{l}83(227 / \\
275)\end{array}$ \\
\hline & $\begin{array}{l}\text { Iris shadow } \geq 0.66 \text { the } \\
\text { distance from limbus to } \\
\text { pupillary margin }\end{array}$ & & & $85(65 / 77)$ & $98(194 / 198)$ & $\begin{array}{l}95(259 / \\
275)\end{array}$ \\
\hline
\end{tabular}

As both the aforementioned tests primarily required the proper use of a flashlight, we attempted to study parameters of these tests and their combinations so that they might not only aid in future development of a smartphone-based screening app but may also be used in clinics to swiftly and accurately detect shallow AC without the use of a smartphone. Upon viewing the results of our study for the anterior perspective, we found that when standardized using the diagnostic criteria of Thomas et $\mathrm{al}^{6}$ (50\% shadow on the nasal iris as shallow), we achieved $100 \%$ sensitivity, $76 \%$ specificity, and $82.5 \%$ accuracy in detection of shallow AC $(\leq 2.7 \mathrm{~mm})$. The temporal perspective achieved the same results while using $0.5 \mathrm{~mm}$ as the cutoff ratio, suggesting that if a clinician were merely able to tell if the midpoint of the pupil was more toward the cornea or temporal limbus, they would be $82.5 \%$ accurate in detecting a shallow AC. Although these parameters provided adequate measures to be used in mass screening, on further analysis of our results, we observed that better accuracy was achieved when criteria of the anterior and temporal perspectives defining shallow AC were changed from a $\leq 0.5$ ratio to a ratio of $\leq 0.34$ in detecting ACD $\leq 2.70 \mathrm{~mm}$. In clinical terms, this translated to $94 \%$ accuracy in detection of ACD $\leq 2.7 \mathrm{~mm}$, when two-thirds or more of the nasal iris is shadowed and only a third or less is illuminated, as displayed in Figure 5B, in comparison to $\mathrm{ACD}$ that is normal (Figure 5A).

On the temporal perspective, when the anteroposterior dimension of the eye from the corneal apex to temporal limbus was divided into three equal parts, if the midpoint of the pupil was found to be in the anterior third, that eye had a higher likelihood of having a shallow AC (Figure 6B) than an ACD which was normal (Figure 6A). Using this criterion for the temporal perspective, we were able to achieve $92 \%$ accuracy in detecting ACD $\leq 2.70 \mathrm{~mm}$. Since 


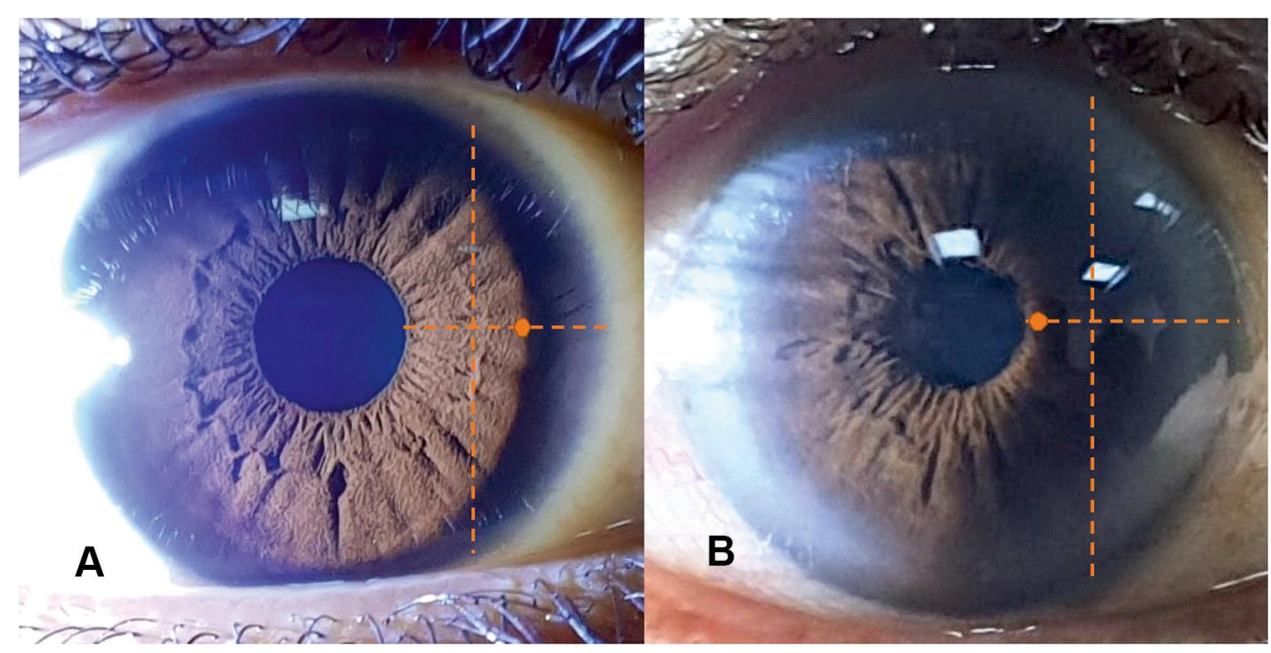

Figure 5 Clinical determination of shallow AC on anterior perspective (flashlight method). The horizontal line denotes the total width of the nasal iris traced from the nasal pupillary edge to the nasal limbus. The vertical line demarcates a temporal third of the total width. The dot on the horizontal line marks the start of the iris shadow. (A) Normal ACD on anterior perspective. The start of the iris shadow is on the nasal side of the vertical line depicting >two-thirds of nasal iris being illuminated. (B) Shallow $A C D$ on anterior perspective. The start of the iris shadow is on the temporal side of the vertical line depicting less than a third of the nasal iris being illuminated.

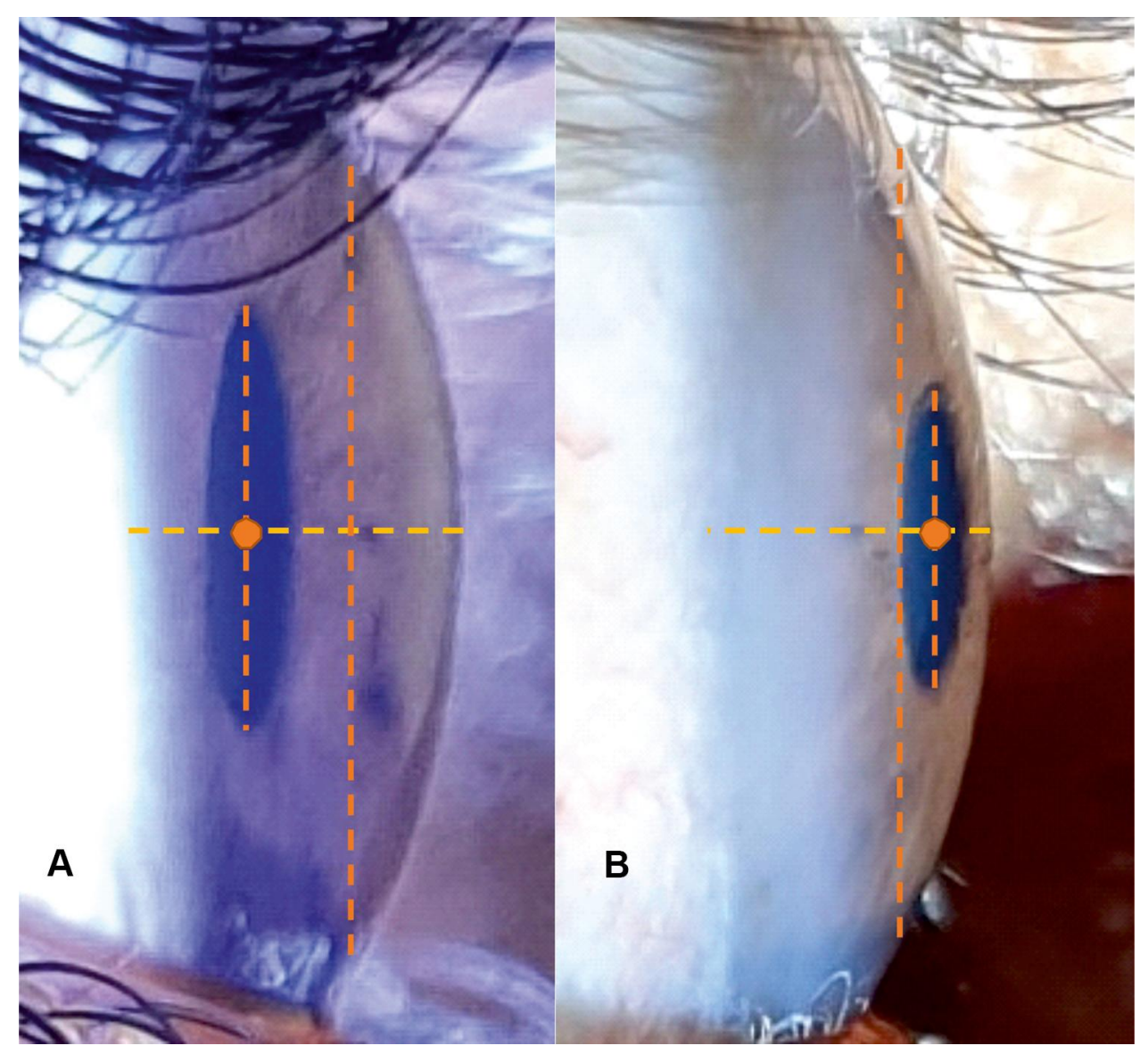

Figure 6 Clinical determination of shallow AC on temporal perspective (temporal perpendicular method). The horizontal line connecting the corneal apex, midpoint of pupil, and temporal limbus denotes the anteroposterior diameter of anterior chamber. The longer vertical line demarcates the anterior third of the anterior chamber. The dot on the horizontal line demarcates the midpoint of the pupil (determined by the shorter vertical line joining the superior and inferior pupillary edge). (A) Normal ACD on temporal perspective. The midpoint of the pupil lies in the posterior two-thirds of the eye. (B) Shallow ACD on temporal perspective. The midpoint of the pupil lies in the anterior third of the eye. 
we employed the same two instruments (smartphone and flashlight) for both the methods, keeping the practicability of these methods in mind, we studied the combined accuracy of the methods, where the eye was termed shallow if either of the tests detected the eye to be shallow. We found that this considerably increased both sensitivity and specificity in detecting a shallow AC. We found that when either of the tests classified an eye as shallow (using 0.34 as the cutoff), combined sensitivity was $91 \%$, combined specificity $98 \%$, and combined accuracy $96 \%$ for detection of shallow ACD.

This translates to $96 \%$ accuracy in detection of a shallow $\mathrm{AC}$ if a clinician using nothing but a flashlight is able to determine if on the anterior perspective, the nasal iris shadow is covering $\geq$ two-thirds of the nasal iris, or if the midpoint of the pupil is in the anterior third of the eye on the temporal perspective.

With minimal training in standardization, these techniques can be incorporated into clinical practice to reliably detect the presence or absence of shallow ACs. However, for mass screening and use by nonophthalmologists, optometrists, and peripheral health workers in the community, the process of image acquisition and analysis needs to be automated by development of a custom device and a smartphone-based application that may instantly be able to detect a shallow AC. For development of an artificial intelligence-powered smartphone app that may be used for mass screening, the data acquired from the ROC curve suggest that a cutoff ratio of 0.4 serves as a near-perfect parameter in detection of a shallow AC, giving a combined sensitivity of $98.7 \%$, combined specificity of $94 \%$, and combined accuracy of $95 \%$. Although ideal, a cutoff of 0.4 is difficult to assess clinically, and hence a 0.34 cutoff is recommended for clinical practice.

The scatterplots, Pearson's coefficient, and $R^{2}$ values for the three variables, showed excellent correlation, suggesting that ratios derived from analysis of anterior and temporal perspectives may not only be a useful tool in detection of shallow ACD but may also serve a possible role in predicting ACD quantitatively. Quantitative determination of ACD of an eye using standardized smartphone imaging requires further studies, and the data obtained in the current study provide preliminary proof of the same.

Despite not being our original aim, during the course of the study, we observed that standard image acquisition provided clear visualization of the anterior segment from two perspectives, which could enable use of these images for teleophthalmology services in areas with poor access to health care, on occasions where a patient has restricted mobility due to systemic comorbidities, or in catering to the growing need for remote consultancy in such situations as the ongoing COVID-19 pandemic. ${ }^{14}$

Although robust, there were a few limitations in this study. The process of image acquisition required an initial learning curve, which in our view can be overcome by development of a device that can hold the smartphone and the flashlight at a fixed angle to each other to facilitate image acquisition. As image acquisition and optical biometry were done in a well-lit room, this may have affected and perhaps overestimated the photogrammetry ratios and ACD values, thereby underestimating the number of eyes with an actual shallow AC $(\leq 2.7 \mathrm{~mm})$. Although this was a possible source of error, a dimly lit or poorly illuminated room was associated with variable pupil size, difficulty in target fixation, and poor image quality, which served as additional potential sources of error. For the purposes of standardization, image acquisition was done in a well-lit room. On both views, the presence of a dense arcus senilis may easily mislead the clinician into falsely interpreting a shallow $\mathrm{AC}$ as a normal one, for which we recommend the clinician interpret the tests only after correctly identifying the nasal and temporal limbus. Photogrammetry of the images was time-consuming, but this can be overcome by development of a smartphone-based app.

In conclusion, photogrammetry of images acquired from anterior and temporal perspectives can detect shallow ACs with high accuracy. The use of this screening technique needs to be evaluated on a large scale for community application, and further research on the reliability of this technique when used by nonophthalmologists needs to be done, for which this study can serve as a foundation.

\section{Data Sharing Statement}

The materials generated from this study have not yet been submitted to any data repository and are not publicly available. They may be acquired from the corresponding author on reasonable request.

\section{Ethics Approval}

This study was performed in line with the principles of the Declaration of Helsinki. Approval was granted by the Ethics Committee of the Manipal Academy of Higher Education (August 14, 2018/IEC 497-2018).

\section{Consent to Participate}

Informed consent was obtained from all participants. 


\section{Consent for Publication}

Patients signed informed consent regarding publishing their data and photographs.

\section{Acknowledgments}

We thank Kasturba Medical College- Manipal and the Manipal Academy of Higher Education for provision of the necessary infrastructure, instruments, and financial support that made this study possible.

\section{Author Contributions}

All authors made substantial contributions to conception and design, acquisition of data, or analysis and interpretation of data, took part in drafting the article or revising it critically for important intellectual content, agreed to submit to the current journal, gave final approval to the version to be published, and agree to be accountable for all aspects of the work.

\section{Funding}

The study received Rs35,000 (US\$450) seed money from the Manipal Academy of Higher Education (parent institute of Kasturba Medical College, Manipal) toward the use of optical biometry.

\section{Disclosure}

The authors declare they have no conflicts of interest.

\section{References}

1. Tham YC, Li X, Wong TY, Quigley HA, Aung T, Cheng CY. Global prevalence of glaucoma and projections of glaucoma burden through 2040: a systematic review and meta-analysis. Ophthalmology. 2014;121(11):2081-2090. doi:10.1016/j.ophtha.2014.05.013

2. Friedman DS, Foster PJ, Aung T, He M. Angle closure and angle-closure glaucoma: what we are doing now and what we will be doing in the future. Clin Experiment Ophthalmol. 2012;40 (4):381-387. doi:10.1111/j.1442-9071.2012.02774.x

3. Paul C, Sengupta S, Banerjee S, Choudhury S. Angle closure glaucoma in rural and urban populations in eastern India-The Hooghly River Glaucoma Study. Indian J Ophthalmol. 2018;66(9):1285-1290. doi:10.4103/ijo.IJO_344_18
4. Marchini G, Pagliarusco A, Toscano A, Tosi R, Brunelli C, Bonomi L. Ultrasound biomicroscopic and conventional ultrasonographic study of ocular dimensions in primary angle-closure glaucoma. Ophthalmology. 1998;105(11):2091-2098. doi:10.1016/ S0161-6420(98)91132-0

5. Kurita N, Mayama C, Tomidokoro A, Aihara M, Araie M. Potential of the pentacam in screening for primary angle closure and primary angle closure suspect. $J$ Glaucoma. 2009;18(7):506-512. doi:10.1097/IJG.0b013e318193c141

6. Thomas R, George T, Braganza A, Muliyil J. The flashlight test and van Herick's test are poor predictors for occludable angles. Aust $N \quad Z \quad J$ Ophthalmol. 1996;24(3):251-256. doi:10.1111/j.14429071.1996.tb01588.x

7. Zamir E, Kong GY, Kowalski T, Coote M, Ang GS. A novel method of quantitative anterior chamber depth estimation using temporal perpendicular digital photography. Transl Vis Sci Technol. 2016;5 (4):10. doi:10.1167/tvst.5.4.10

8. Thomas R, Parikh R, Muliyil J, Kumar RS. Five-year risk of progression of primary angle closure to primary angle closure glaucoma: a population-based study. Acta Ophthalmol Scand. 2003;81 (5):480-485. doi:10.1034/j.1600-0420.2003.00135.x

9. Pan CW, Wong TY, Chang L, et al. Ocular biometry in an urban Indian population: the Singapore Indian Eye Study (SINDI). Invest Ophthalmol Vis Sci. 2011;52(9):6636-6642. doi:10.1167/iovs.107148

10. Van Herick W, Shaffer RN, Schwartz A. Estimation of width of angle of anterior chamber. Incidence and significance of the narrow angle. Am J Ophthalmol. 1969;68(4):626-629. doi:10.1016/0002-9394(69) 91241-0

11. Mandell MA, Pavlin CJ, Weisbrod DJ, Simpson ER. Anterior chamber depth in plateau iris syndrome and pupillary block as measured by ultrasound biomicroscopy. Am J Ophthalmol. 2003;136 (5):900-903. doi:10.1016/s0002-9394(03)00578-6

12. Vargas E, Drance SM. Anterior chamber depth in angle-closure glaucoma. Clinical methods of depth determination in people with and without the disease. Arch Ophthalmol. 1973;90(6):438-439. doi:10.1001/archopht.1973.01000050438005

13. Congdon NG, Quigley HA, Hung PT, Wang TH, Ho TC. Screening techniques for angle-closure glaucoma in rural Taiwan. Acta Ophthalmol Scand. 1996;74(2):113-119. doi:10.1111/j.16000420.1996.tb00053.x

14. Williams AM, Kalra G, Commiskey PW, et al. Ophthalmology practice during the coronavirus disease 2019 pandemic: the University of Pittsburgh experience in promoting clinic safety and embracing video visits. Ophthalmol Ther. 2020;9(3):1-9. doi:10.1007/s40123-02000255-9

15. He M, Huang W, Friedman DS, Wu C, Zheng Y, Foster PJ. Slit lamp-simulated oblique flashlight test in the detection of narrow angles in Chinese eyes: the Liwan eye study. Invest Ophthalmol Vis Sci. 2007;48(12):5459-5463. doi:10.1167/iovs.07-0670
Clinical Ophthalmology

\section{Publish your work in this journal}

Clinical Ophthalmology is an international, peer-reviewed journal covering all subspecialties within ophthalmology. Key topics include: Optometry; Visual science; Pharmacology and drug therapy in eye diseases; Basic Sciences; Primary and Secondary eye care; Patient Safety and Quality of Care Improvements. This journal is indexed on PubMed
Central and CAS, and is the official journal of The Society of Clinical Ophthalmology (SCO). The manuscript management system is completely online and includes a very quick and fair peer-review system, which is all easy to use. Visit http://www.dovepress.com/ testimonials.php to read real quotes from published authors. 